\title{
Perspectives on Evidence-Based Healthcare for Women
}

\author{
Maya J. Goldenberg, Ph.D.
}

\section{Introduction}

W E LIVE IN AN AGE OF evidence-based healthcare, where the concept of evidence has been avidly and often uncritically embraced as a symbol of legitimacy, truth, and justice. By letting the evidence dictate healthcare decision making from the bedside to the policy level, the normative claims that inform decision making appear to be negotiated fairly-without subjectivity, prejudice, or bias. ${ }^{1,2}$ Thus, the term "evidence-based" is typically read in the health sciences as the empirically adequate standard of reasonable practice and a means for increasing certainty. Supporters believe that evidence-based medicine (EBM) can introduce rational order to the deliberative processes of healthcare decision making. ${ }^{3-5}$ It is perhaps puzzling, then, to come across critical perspectives (typically arising from the humanities and the more theory-driven social sciences) raising concerns about a seeming technogovernance being introduced by this deferral to the evidence where power interests can be obfuscated by way of technical resolve. ${ }^{6,7}$ The critics holding this minority view argue that technological solutions to problems of knowledge and practice cannot replace medicine's normative content. Against EBM's democratic leanings toward transparency and accountability, medical criteria alone cannot decide valueladen ethically charged decisions. 3,8

This conflict of views is present in the field of women's health. Supporters argue that an evidence-based approach to women's health will improve health outcomes by critically analyzing the evidence base of women's health research: identifying gaps and assessing the quality of the available evidence. ${ }^{1,9}$ Critics, however, worry that evidence-based practice will limit meaningful research into the sociopolitical determinants of women's health by narrowing the range of admissible research methods and the types and sources of reliable evidence. ${ }^{10-12}$ Could an undervaluing of qualitative methods, for example, limit the important work of giving women voice and bringing their experience to bear on the healthcare encounter?

I find the unfolding of the EBM debate in women's health particularly interesting and worthy of focused attention because, unlike many other medical specialties that have largely suppressed dissent toward the evidence-based program, women's health uniquely houses both insider and outsider perspectives with respect to the institutional knowledge and practices of biomedicine. This has to do with the evolution of the women's health movement. The women's health specialization originated as an outlier of biomedicine, growing out of a radical feminist grassroots movement that fostered a critical and questioning attitude toward the mainstream practices of biomedicine, which often failed to meet the specific needs of women or kept women uninformed about the issues that mattered to us. The movement was remarkably successful in bringing attention to the unique healthcare needs of women, resulting in the field being incorporated into that very mainstream both professionally and ideologically. ${ }^{13}$ It is, therefore, not surprising that some women's health researchers will see the largely institutionally sanctioned evidence-based program as a vital tool for furthering the healthcare needs of women, whereas others will suspect implicit gender bias in its methodological assumptions.

EBM is popularly defined as "the conscientious, explicit, and judicious use of current best evidence in making decisions about the care of individual patients. ${ }^{14}$ It was initially framed as a "new paradigm" in medicine that "de-emphasize[d] intuition, unsystematic clinical experience, and pathophysiological rationale as sufficient grounds for clinical decisionmaking and stresse[d] the examination of evidence from clinical research." ${ }^{15}$ Although the rhetoric of paradigms and revolutions has been toned down in more recent iterations, the promise still remains. EBM quickly rose to prominence in academic medicine throughout the 1990s because it promised to revolutionize medicine through the systematic evaluation of clinical research and the application of that research into bedside care. Even the critics of EBM will agree that as new discoveries continue to expand the breadth of medical interventions, treatments, and methods of care, the need for a more systematic approach to evidence development and application becomes increasingly critical. Without better information about the effectiveness of different treatment options, the resulting uncertainty can lead to the delivery of services that may be unnecessary, unproven, or even harmful. Improving the evidence base for medicine holds great potential to increase the quality and efficiency of medical care.

There is a seeming obviousness to the evidence-based program. Some critics have asked, "What other kind of medicine can there be?" The epidemiological research suggests that the founding members of the evidence-based movement were correct in their claims that much of clinical medicine consisted of untested hunches, unsystematic clinical experience, and inferential pathophysiological rationale rather than empirical evidence. And so the move from the old ways of biomedicine to the new evidence-based approach is difficult to argue against.

Department of Philosophy, University of Guelph, Ontario, Canada. 
Yet critics will insist that the seeming common sense and obviousness of EBM's methodological and epistemic claims result from their having been stripped of the social context of medical practice. Just as critics within science studies have demonstrated that science is never value free and that the myth of value neutrality distorts actual scientific practice, ${ }^{16-19}$ the same concerns arise in medicine. In an age when the institutional power of medicine is suspect, a model that represents biomedicine's power as disinterested should give pause.

Furthermore, the common sense of the claim, "good medicine depends on good evidence," only holds as long as it remains at the level of platitude. Supporters and critics alike agree that medical decisions should be based on the best evidence, but it is as soon as one moves beyond platitudes and tries to supply specific criteria for what counts as "the best evidence" that one enters controversial and contested territory with respect to women's health. We want to pay attention to what constitutes best evidence in EBM because this is crucial for getting past the rhetoric and attending to what evidence-based practice offers to women's health and other areas of healthcare. Looking through the EBM movement's programmatic literature, we find Davidoff et al.'s often cited five tenets of EBM, with tenet number four instructing us that identifying the best evidence for clinical decision making involves "using epidemiological and biostatistical ways of thinking" [emphasis added]. ${ }^{20}$ This statement refers to EBM's conceptual grounding in clinical epidemiology.

\section{Clinical Epidemiology: The Grounding for Evidence-Based Medicine}

The term "clinical epidemiology" is derived from its two parent disciplines: clinical medicine and epidemiology. It is clinical because it seeks to answer clinical questions and to guide clinical decision making with the best available evidence. It is epidemiological because many of the methods used to answer these questions have been developed by epidemiologists and because the care of individual patients is seen in the context of the larger population of which the patient is a member. EBM relies on population-based research, namely, large clinical trials, rather than individual case reports, and works to eliminate clinical practice variations across geographical location, thereby improving health outcomes overall. The placement of the randomized controlled trial at the top of the hierarchy of methods as the gold standard of medical research is also demonstrative of epidemiological commitments. These trials are effective in filtering out selection and allocation bias when blinding and randomization are properly organized, and they produce relevant averages with respect to population outcomes.

Until clinical epidemiology was first introduced in the 1930s to signal attempts by some epidemiologists to move their expertise closer to the bedside, public health and clinical medicine were regarded as very distinct disciplines, as the former focused on population health while the latter addressed the individual patient. Clinical epidemiology had a difficult start insofar as it breeched well-established oppositional distinctions between public health and curative medicine, epidemiological and clinical knowledge, and population vs. individual patient care. It only came to prominence in the 1980s when a group of professors of medicine at McMaster
University, in Hamilton, Ontario, Canada, who shared a conviction that the scientific base of clinical practice should be strengthened, published the first edition of the key textbook Clinical Epidemiology, ${ }^{21}$ which was the precursor to EBM. That research group later became the famed Evidence-Based Medicine Working Group. ${ }^{15}$

What we are starting to see is that EBM's seemingly obvious connection between evidence and modern medicine obscures the major shift that occurred in what was seen to count as best evidence within the world of academic medicine with the introduction of EBM. One commentator has characterized the ascendancy of evidence-based approaches in clinical medicine as the triumph of statistics over clinical commonsense and probabilistic knowledge over deterministic reasoning. ${ }^{22}$ EBM also distinguishes itself from pre-evidence-based biomedicine by its orientation toward outcomes research, whereas biomedicine is more dependent on bench science. Biomedical research involves laboratory science that aims to reveal the mechanisms of medical cause and effect in order to determine what ought to be effective. EBM, in contrast, investigates the effects of a health service or organization of services on the health, function, or quality of life of the patient. It seeks to generate probabilistic knowledge regarding what is likely to work, for whatever reason. ${ }^{23,24}$ Biomedical science is seen by some in health informatics to be at the service of evaluative science in treatment decision making (and not the other way around). The role of biomedicine is to generate ideas and technologies, whereas evaluative science provides the necessary clinical information linking treatments to outcomes. ${ }^{25}$ When some of the doubters challenge that biomedicine had indeed always been evidence based-what other kind of medicine could there be?-they are missing EBM's novelty with respect to the standard for what counts as best evidence. Such is the significance that clinical epidemiology is now being held to be a basic medical science. ${ }^{26}$

To return to the disagreement about evidence-based approaches to women's health, women's health research can find and has found much value in evidence-based practices. The demand for evidence-based approaches can eliminate previously unfounded practices that have been harmful or not beneficial to women. It was an evidence-based trial that led to important exposure of the harms of hormone replacement therapies (HRT) to postmenopausal women and the end of its widespread use. ${ }^{27}$ A review of the outcomes associated with breast self-examination has caused an uproar among breast cancer activists, as no positive association was found between self-examination and improved breast cancer outcomes. ${ }^{28}$ The uptake of these findings is still being negotiated.

Because medicine has historically been so marked by sexist assumptions about women and their bodies, many women's health researchers will applaud the call for evidence. The less theoretical privilege and untested biases granted to clinical medicine, the better! Also, by being geared toward measuring patient outcomes, outcomes research can ask the questions that patients and their practitioners want to know-for example, What conditions lead to disease? How accurate are the tests used for disease diagnosis? How does treatment change the course of disease?-rather than more theoretical investigations into biological mechanisms and disease causation.

The critics of evidence-based approaches to women's health have good reason to challenge this methodology, however. We know that EBM offers a technology for patient 
management that applies population-based data to the care of individuals whose personal responses to the health intervention in question will differ from the trial literature's reported collective experience. Numerous critics have argued that EBM is thin on the knowledge-translation piece: How exactly do we extrapolate from averaged patient findings in highly controlled settings to the real-life circumstances of particular patients? The underrepresentation of women in clinical trials is well documented, ${ }^{29-31}$ and even a recent study contravening this claim still admits to infrequent analysis of trial results by sex. ${ }^{32}$ There are numerous past examples of poor extrapolation from trial data to women's care that either have been detrimental to women or have excluded women from the benefits of therapeutic discoveries. Although the problem of gender bias, as well as racial and age bias, in clinical trials is well recognized and well documented, change has been slow. It seems that EBM's theoretical commitments could have been channeled into an effort to change this egregious habit in medical research and the resulting gap in the evidence, but this has not been the case. Instead, EBM has been implicated for the past mistakes of medicine because it presents much of this (past) evidence as authoritative. It may even reify much of the thinking and methods that allowed for the gaps in the research to occur in the first place.

Because the research base is problematic, the resulting clinical practices are corrupted. EBM strives to insert research evidence into clinical practice by offering important timesaving strategies for clinicians to make informed choices: structured abstracts and clinical summaries digest the enormous quantities of literature into decisive verdicts and implementable actions. ${ }^{33,34}$ These guidelines often act as rules rather than suggestions in the clinical setting, with a damaging straightjacket effect on clinicians and a loss of important sources of knowledge: the patient's preferences and values, the clinician's experience and know-how. ${ }^{35}$

\section{Negotiating the Conflict over Evidence-Based Women's Health}

Feminist scholars in science studies and the medical humanities have paid significant attention to scientific research because of the recognized sociopolitical stakes of knowledge and knowledge production. ${ }^{36-38}$ Women have historically suffered numerous exclusions in the name of science, for instance, in biological and psychological explanations of women's supposed cognitive, emotional, and moral inferiority to men. In some cases, these conclusions came from blatantly bad science: false conjectures or poor inferences from the data, for example, to support sexist political agendas. In other cases, sexist assumptions crept unassumingly into a supposedly neutral scientific method. As a result, feminist science studies researchers question the feasibility of valuefree science. The experience and knowledge that even the most rigorous scientists bring to bear on their practice will include those shaped by the social relations of gender, race, and class that characterize our social world. Stricter methodological controls cannot filter out all intrusions of value into science. The best they can do is manage which ones enter and how they affect the scientific process.

This view of the inseparable relationship between science and values should not be understood to be dismissive of science, but rather a gesture toward a more accurate under- standing of the connections between knowledge and social and political relations. This is useful for the EBM debate. Evidence certainly features significantly in modern healthcare, but the rhetorical power of evidence should be viewed cautiously and addressed critically. Personal, professional, and institutional values inevitably intrude on science; thus, the image of objective science being value neutral, or free from subjective bias, is a fiction.

Devries and Lemmens ${ }^{39}$ have argued that evidence is a social product, influenced by the variable power and authority held by different stakeholders, such as patients, researchers, hospital administrators, clinicians, and policymakers, in producing and determining the parameters for what counts as evidence. In other words, evidence is socially negotiated terrain. Although evidence is held up to methodological standards of rigor, those standards do not operate outside of the social context, nor do they circumvent the sociality of science. For example, pharmaceutical industry-funded trials are four times more likely than publicly funded trials to produce favorable results for their products, despite both sources scoring high for methodological rigour. ${ }^{40}$ Strict adherence to the rules can reduce or eliminate some forms of bias but also can ignore or even obscure other unwanted sources that compromise the evidence. This is why the evidence-based focus on scientific rigor is useful in some places but suspicious in others.

The critics are right to ask the challenging question: Whose evidence is setting the standard of best practice? To do this is not to give up on science and return to the old days of hunches and untested habits. Left without evidentiary checks, rampant gender bias can enter into healthcare and seriously compromise the health and well-being of women. Instead, in response to the finding that our values and assumptions influence science, what is called for is transparency and public discussion regarding those values.

Bioethics and social research have a place here. With this more nuanced account of what evidence is and how it operates, the question of what is the best evidence to ground women's health research and practice is no longer a technical question fully answerable by methodological and careful science. Social science and humanities research can offer insight and investigation into which power structures limit or enable women's healthcare. Research ethics needs to go beyond the monitoring of trial participant consent documents and other patient protections in order to engage in the larger or structural questions: Which research questions get asked and which ones get ignored? How are research questions approached? What interests influence the production, proliferation, and uptake of evidence? How is research being incorporated into clinical guidelines? These questions cannot be loaded onto the policing role of our already overworked research ethics boards. Instead, a culture of support for researchers, healthcare institutions, and funders is required to enable change. That could be good for women's health and other areas of healthcare as well.

To conclude, by asking what counts as best evidence in the evidence-based program, we get past the seeming obviousness of the movement and can then concretely investigate what an evidence-based approach offers to women's health and beyond. This review of the debate over evidence-based women's health is intended to demonstrate the good and the bad, with an eye toward what role healthcare practitioners, researchers, and ethicists can play in promoting the best. 


\section{Disclosure Statement}

The author has no conflicts of interest to report.

\section{References}

1. Owen WF, Szczech LA, Frankenfield DL. Healthcare system interventions for inequality in quality: Corrective action through evidence-based medicine. J Natl Med Assoc 2002;94 (Suppl 8):83S-91S.

2. Rogers W. Does evidence-based medicine offer fair benefits for all? Virtual Mentor 2004;6:12. Available at virtualmentor .ama-assn.org/2004/12/oped1-0412.html

3. Dickenson DL. Can medical criteria settle priority-setting debates? The need for ethical analysis. Health Care Anal 1999;7:131-137.

4. Sackett DL, Straus SE, Richardson WS, et al. Evidence-based medicine: How to practice and teach EBM, 2nd ed. London: Churchill Livingstone, 2000.

5. Haynes RB. What kind of evidence is it that evidence-based medicine advocates want health care providers and consumers to pay attention to? BMC Health Serv Res 2002;2:3. Available at www.biomedcentral.com/1472-6963/2/3

6. Denny K. Evidence-based medicine and medical authority. J Med Humanities 1999;20:247-263.

7. Holmes DL, Murray SJ, Peron A, Rail G. Deconstructing the evidence-based medicine discourse in health sciences: Truth, power and fascism. Int J Evid Based Healthcare 2006;4:180-186.

8. Goldenberg MJ. Evidence-based ethics? On evidence-based practice and the "empirical turn" from normative bioethics. BMC Med Ethics 2005;6:11. Available at www.biomedcentral .com/1472-6939/6/11

9. Bierman AS, ed. Project for an Ontario women's health evidence-based report: Volume 1. Toronto, 2009: vol 1. Available at www.powerstudy.ca

10. Rogers W. Evidence-based medicine and women: Do the principles and practice of EBM further women's health? Bioethics 2004;18:50-71.

11. Oakley A. Experiments in knowing: Gender and method in social science. Oxford: Polity Press, 2000.

12. Doyal L. What makes women sick: Gender and the political economy of health. Basingstoke: Macmillan Press, 1995.

13. Goldenberg MJ. Health. In: Smith B, ed. Oxford encyclopedia of women in world history. New York: Oxford University Press, 2008:440-442.

14. Sackett DL, Rosenberg WMC, Muir Gray JA, Haynes RB, Richardson WS. Evidence based medicine: What it is and what it isn't. BMJ 1996;312:71-72.

15. Evidence-Based Medicine Working Group. Evidence-based medicine: A new approach to teaching the practice of medicine. JAMA 1992;268:2420-2425.

16. Anderson ES. Knowledge, human interests, and objectivity in feminist epistemology. Philosoph Topics 1995;23:27-58.

17. Feyerabend PK. Against method, 3rd ed. London: Verso, 1993.

18. Giere RN. Science without laws. Chicago: University of Chicago Press, 1999.

19. Proctor R. Value-free science? Purity and power in modern knowledge. Cambridge, MA: Harvard University Press, 1991.

20. Davidoff F, Haynes, B, Sackett, D, Smith R. Evidence based medicine. BMJ 1995;310:1085-1086.

21. Sackett DL, Haynes RB, Tugwell P. Clinical epidemiology: A basic science for clinical medicine. Boston: Little, Brown \& Co., 1991.
22. Polychronis A, Miles A, Bentley P. The protagonists of "evidence-based medicine": Arrogant, seductive, and controversial. J Eval Clin Pract 1996;2:9-12.

23. Tanenbaum SJ. Knowing and acting in medical practice: The epistemological politics of outcomes research. J Health Pol Policy Law 1994;19:27-44.

24. Goldenberg MJ. Iconoclast or creed? Objectivism, pragmatism, and the hierarchy of medicine. Perspect Biol Med 2009;52:168-187.

25. Wennberg JE. AHCP and the strategy for health care reform. Health Affairs 1992;11:67-71.

26. Fletcher RW. Clinical epidemiology: The essentials, 4th ed. Baltimore: Lippincott, Williams \& Wilkins, 2005.

27. Writing Group for the Women's Health Initiative Investigators. Risks and benefits of estrogen plus progestin in healthy postmenopausal women: Principal results from the Women's Health Initiative randomized controlled trial. JAMA 2002;288:321-333.

28. Baxter N, with the Canadian Task Force on Preventive Health Care. Preventive health care, 2001 update: Should women be routinely taught breast self-examination to screen for breast cancer? Can Med Assoc J 2001;164:1837-1846.

29. Holcroft A. Gender bias in research: How does it affect evidence based medicine? J R Soc Med 2007;100:2-3.

30. Rogers WA. Evidence-based medicine and justice: A framework for looking at the impact of EBM upon vulnerable or disadvanged groups. J Med Ethics 2004;30:141-145.

31. Harris DJ, Douglas PS. Enrollment of women in cardiovascular clinical trials funded by the National Heart, Lung and Blood Institute. N Engl J Med 2000;343:475-480.

32. Rogers WA, Ballentyne AJ. Exclusion of women from clinical research: Myth or reality? Mayo Clin Proc 2008;83:536-542.

33. Haynes RB. Of studies, syntheses, synopses, and systems: The " $4 S^{\prime}$ " evolution of services for finding current best evidence. Evidence-Based Med 2001;6:36-38.

34. Haynes RB. Of studies, syntheses, synopses, summaries, and systems: the " $5 \mathrm{~S}$ " evolution of information services for evidence-based healthcare decisions. Evidence-Based Med 2006;11:162-164.

35. Loewy E. Ethics and evidence-based medicine: Is there a conflict? Med Gen Med 2007;9:30. Available at www .medscape.com/viewarticle/559977

36. Code L. What can she know? Taking subjectivity into account. Ithaca: Cornell University Press, 1991.

37. Longino H. Science as social knowledge: Values and objectivity in scientific inquiry. Princeton: Princeton University Press, 1990.

38. Grasswick H, ed. Feminist epistemology and philosophy of science: Power in knowledge. New York: Springer Books, 2010.

39. DeVries $R$, Lemmens $T$. The social and cultural shaping of medical evidence: Case studies from pharmaceutical research and obstetric science. Soc Sci Med 2006;62:2694-2706.

40. Lexchin J, Bero LA, Djulbegovic B, Clark O. Pharmaceutical industry sponsorship and research outcome and quality: Systematic review. BMJ 2003;326;1167-1170.

Address correspondence to: Maya J. Goldenberg, Ph.D. Department of Philosophy University of Guelph Guelph, Ontario, N1G 2W1

Canada

E-mail: mgolden@uoguelph.ca 